\title{
EDITORIAL
}

\section{ARQUIVOS DO INSTITUTO BIOLÓGICO - 80 ANOS DIVULGANDO CONHECIMENTO}

Criada de forma discreta, sem nenhuma apresentação formal pelo seu mentor e primeiro Diretor Geral do Instituto Biológico(IB), Dr. Arthur Neiva, a revista, então denominada “ Archivos do Instituto Biológico de Defesa Agrícola e Animal”, era pela primeira vez publicada em dezembro de 1928, um ano após a criação do Instituto Biológico.

Em seus primeiros númerosjá se destacavam os artigos de grandes nomes da ciência referindo-se aos estudos de descrições de novas espécies, investigações de doenças e pragas dos animais e vegetais, sempre considerando a temática de sanidade animal e vegetal em harmonia com a missão pela qual a Instituição foi criada, em 26 de dezembro de 1927, sob a Lei $\mathrm{n}^{\mathrm{O}} 2.243$.

Entre os anos de1928 e 2007 o número de trabalhos publicados na revista foi de 2.142, sendo que destes, 1.195 foram de autores provenientes do IB, 310 de autoria mista (pesquisadores do IB e externos) e 517 de autores de outras instituições de pesquisa e ensino. O período de 2003 a 2005 concentrou o maior número de artigos publicados (268). O número de autores que participaram da revista (1928-2007) foi de 6.526, provenientes de praticamente todos os estados brasileiros e 27 países. Esses números revelam a importância e a dimensão do alcance de nossa revista.

Nesses 80 anos de existência, a revista "Arquivos do Instituto Biológico" passou por várias mudanças, sejam elas tanto de forma quanto de conteúdo, sempre procurando ajustar-se ao seu tempo, porém sem perder o foco institucional. Nas normas atuais aceitam-se, para publicação, artigos originais de pesquisa científica em sanidade animal e vegetal voltados para o agronegócio e suas implicações no agroambiente, incluindo nesse escopo a qualidade e segurança alimentar, requisitos que estão contidos na missão institucional. Artigos sobre pragas sinantrópicas também são aceitos e representa uma área institucional em franca expansão.

A modernização e a demanda levaram, no ano 2000, a publicar a revista, além da forma impressa, sob o sistema "on-line" e, em 2002, ela passou a ser trimestral (quatro números/ano). Submetida à classificação de periódicos da Coordenação de Aperfeiçoamento de Pessoal de Nível Superior (CAPES), a revista "Arquivos do Instituto Biológico" foi qualificada como "A" de âmbito de circulação nacional nas seguintes áreas do conhecimento: Ciência de Alimentos, Ciências Agrárias, Medicina Veterinária e Zootecnia/recursos pesqueiros.

Esse caminho vitorioso percorrido pela revista, superando obstáculos ao longo de 80 anos e mantendo-se como um canal de comunicação científica não só do Instituto Biológico, mas também servindo a outras instituições de ensino e pesquisa dentro e fora do Brasil, só foi possível graças a determinação de funcionários idealistas e comprometidos com o Instituto Biológico. Muitos fizeram parte dessa missão e aqui registramos nosso reconhecimento as equipes que se sucederam ao longo de 8 décadas, representadas pelos seguintes editores: Arthur Neiva, José Reis, S. Gonçalves da Silva, Anderson C. de Andrade, Jorge Abrahão, Domingos A. Oliveira, José Reis July, Manuel Alberto da Silva Castro Portugal, Maria Mércia Barradas, Márcia Maria Rebouças e Silvia Regina Galleti.

Segue-se agora um novo tempo, caminha-se para os 100 anos e continuará a revista "Arquivos do Instituto Biológico" agregando modernidade a sua rica história e servindo também a novas demandas como é o caso do recém criado Curso de Pós-Graduação em Sanidade, Segurança Alimentar e Ambiental no Agronegócio, oferecido pelo Instituto Biológico. Que as gerações futuras possam testemunhar a importância desse meio de comunicação institucional, instrumento estratégico para a divulgação de ciência e tecnologia.

Antonio Batista Filho Diretor Geral

Instituto Biológico

São Paulo - SP - Brasil 